\title{
Development of a bioactive implant for repair and potential healing of cranial defects
}

\author{
Technical note
}

\author{
Thomas Engstrand, M.D., Ph.D., ${ }^{1}$ Lars Kihlström, M.D., M.B.A., ${ }^{2}$ Erik Neovius, M.D., ${ }^{1}$ \\ Ann-Charlott Docherty Skogh, M.D., Ph.D., ${ }^{1}$ T. Kalle Lundgren, M.D., Ph.D., ${ }^{1}$ \\ Hans Jacobsson, M.D., Ph.D., ${ }^{3}$ Jan Bohlin, ${ }^{4}$ Jonas Åberg, Ph.D., 5 \\ and Håkan Engqvist, Ph.D. ${ }^{5}$
}

\begin{abstract}
${ }^{1}$ Stockholm Craniofacial Centre, Department of Molecular Medicine and Surgery, Plastic Surgery Section; ${ }^{2}$ Department of Clinical Neuroscience, Neurosurgical Section; ${ }^{3}$ Department of Radiology and Nuclear Medicine, Karolinska University Hospital and Karolinska Institute, Stockholm; and ${ }^{4}$ Department of Chemistry, Polymer Chemistry Section, and ${ }^{5}$ Department of Engineering Sciences, Applied Materials Science Section, Uppsala University, Uppsala, Sweden
\end{abstract}

\begin{abstract}
The repair of complex craniofacial bone defects is challenging and a successful result is dependent on the size of the defect, quality of the soft tissue covering the defect, and choice of reconstruction method. The objective of this study was to develop a bioactive cranial implant that could provide a permanent reconstructive solution to the patient by stimulating bone healing of the defect. In this paper the authors report on the feasibility and clinical results of using such a newly developed device for the repair of a large traumatic and therapy-resistant cranial bone defect. The patient had undergone numerous attempts at repair, in which established methods had been tried without success. A mosaic-designed device was manufactured and implanted, comprising interconnected ceramic tiles with a defined calcium phosphate composition. The clinical outcome 30 months after surgery revealed a restored cranial vault without postoperative complications. Computed tomography demonstrated signs of bone ingrowth. Examination with combined ${ }^{18} \mathrm{~F}$-fluoride PET and CT provided further evidence of bone healing of the cranial defect.

(http://thejns.org/doi/abs/10.3171/2013.6.JNS1360)
\end{abstract}

\section{$\begin{array}{lcc}\text { KeY WoRds } & \text { cranial implant } \\ \text { regeneration } & \bullet & \text { surgical technique }\end{array}$}

$\mathrm{S}$ TATE-OF-THE-ART techniques in large cranial repair involve either autologous bone transplantation, the use of alloplastic implants, or combinations thereof. ${ }^{17}$ These techniques are associated with bone resorption, or infection and protrusion through the skin, respectively, which may limit their clinical use in difficult cases. Current synthetic implant materials for cranioplasty are produced using different polymers, metals, or sintered hydroxyapatite. . $^{3,414,20}$ Polymer and metallic materials are inert and do not posses bioactive characteristics. A number of bioactive compounds, including bioceramics and osteoinductive cytokines, possess stimulatory effects on bone growth, but their usage is limited to healing fractures and smaller defects at orthotopic sites or in bone fusion procedures. ${ }^{13,24}$ Regeneration of larger segmental bone defects in humans is considerably more challenging. For these cases several operative procedures are generally needed and the reconstruction methods typically necessitate the

\footnotetext{
Abbreviations used in this paper: $\beta$-PPi $=\beta$-calcium pyrophosphates; $\beta$-TCP $=\beta$-tricalcium phosphate.
}

use of scaffolds supplemented with autologous bone or cell transplantation to possibly gain healing response..$^{19,23}$

A scaffold that provides osteoconduction and osteoinduction, adjustable geometry in the operating room, and sufficient mechanical strength is highly sought in the treatment of complex or large bone defects. One method not previously explored is to use injectable bioceramics and mold complex shapes outside the body. After hardening, the implant can be sterilized and subsequently implanted. By molding bioceramics on a titanium mesh in a mosaic design, mechanical stability can be combined with good handling properties. Injectable calcium phosphate bioceramics can be found in either the brushite- (acidic) or hydroxyapatite-forming (neutral) therapeutic chemistry. ${ }^{5}$ A third category of therapeutic chemistry is to use monetite-forming cements, although this has not been as extensively explored as the first 2 categories. ${ }^{1}$ Brushite cements resorb relatively quickly in vivo, whereas apatite cements are considered to be almost insoluble. ${ }^{2}$ Monetite has a solubility and resorption rate in between brushite and apatite. ${ }^{5}$ In addition to the 3 described cement phases, the 
option to add other noncementitious phases to obtain specific properties also exists, such as $\beta$-TCP or $\beta$-PPi. ${ }^{11,12} \mathrm{We}$ report the clinical effects of using an adjustable scaffold with a specific calcium phosphate composition, molded in a mosaic design and interconnected by a titanium mesh, in the repair of a cranial defect in a severely injured patient.

\section{Methods}

A mold designed in a mosaic pattern was manufactured using a computer-aided design/computer-aided manufacturing technique. Crossing titanium wires forming a mesh were used to interconnect individual ceramic tiles molded in hexagonal cavities measuring $8 \times 8 \times 4 \mathrm{~mm}$ and with $1.5 \mathrm{~mm}$ of interspace between each tile (Fig. 1 left). A ceramic compound comprising monocalcium phosphate and $\beta$-TCP powder mixed with glycerol was used to enable molding under controlled conditions. The mosaic structure was allowed to harden overnight in sterile water. After removal from the mold, the implant was left in sterile water 48 hours to reduce the glycerol content. The mosaic-designed cranial implant measuring $100 \times$ $100 \mathrm{~mm}$ was subsequently heat sterilized at $121^{\circ} \mathrm{C}$ for 20 minutes before use. The sterilized ceramic was analyzed for phase composition using x-ray diffraction (Bruker D8 Diffractometer), with scanning angles from $5^{\circ}$ to $60^{\circ}$, step size 0.0143 , and 1 -second dwell time. Fractions of different calcium phosphate components were calculated using Rietveld refinement. The microstructure was visualized using scanning electron microscopy (LEO 1550, Zeiss). A thin layer of gold/palladium was sputtered onto the surface prior to analysis to avoid charging effects. During analysis the acceleration voltage was set to $3.0 \mathrm{kV}$.

\section{Illustrative Case}

History and Presentation. A 53-year-old patient who was a smoker was referred to the craniofacial center from the neurosurgical department. Several years earlier he was savagely beaten by his neighbor with a hammer and suffered from a large temporoparietal cranial bone defect measuring $80 \times 90 \mathrm{~mm}$. The patient had been operated on extensively, in a total of 24 surgical procedures. He had previously received autologous bone grafts, polymethyl methacrylate cement, and a titanium implant, which all failed due to either resorption or infections and protrusion through the skin. Because conventional repair methods failed, an ethical application was submitted to and approved by the Stockholm ethical review board involving humans (Dnr 03-244) and informed consent was obtained. Our initial attempt was to induce new bone formation in situ and we applied bone morphogenetic protein-2 (InductOs, Pfizer) locally but without therapeutic effects.

Examination Using PET/CT. Examination was performed using a Biograph 64 TruePoint PET/CT scanner (Siemens Medical Solutions). Sixty minutes after intravenous administration of $300 \mathrm{MBq}$ of ${ }^{18} \mathrm{~F}$-fluoride, a PET/ $\mathrm{CT}$ examination of the calvaria was initiated. The examination began with a diagnostic (full-current) $\mathrm{CT}$ without administration of contrast medium. The PET examination followed directly afterward. Acquisition was made during 3 minutes. Images were reconstructed with CT-based attenuation and scattering corrections using the iterative ordered subset expectation maximization reconstruction algorithm of the manufacturer.

Operative Procedure. Prior to surgery an analysis of the hardened ceramic composition revealed the phases monetite, $\beta$-TCP, $\beta$-PPi, and brushite (Fig. 1 lower right). Scanning electron microscopy showed calcium phosphates with a grain size of approximately $1-2 \mu \mathrm{m}$ and a platelike structure (Fig. 1 upper right). A mosaic-designed device was subsequently manufactured.

The bone defect was exposed through a standard bicoronal cranial skin flap. The soft tissue covering the defect was predominantly fibrotic in nature due to previous injury and surgery. The sterilized ceramic implant was cut and adjusted to fit into the defect and fixated by titanium plates and screws. Perioperative antibiotic prophylaxis (cloxacillin, Stragen Nordic) was administered.

Postoperative Course. The patient recovered from surgery without complications, demonstrated no immediate local or systemic side effects, and left the hospital 3 days after surgery. Postoperative CT scans confirmed the correct position of the implant, covering the original bone defect. Clinical follow-up examinations every third month until 30 months after surgery revealed a well-tolerated implant without signs of infection, inflammation, or thinning of the soft tissues covering the implant (Fig. 2A). A progressive condensation of the ceramic tiles, especially at the anterior part of the implant, was evident from consecutive CT scans (Fig. 2B and C).

A functional analysis on bone growth was performed using ${ }^{18} \mathrm{~F}$-fluoride PET/CT scans after 27 months (Fig. 3). The fluoride ion exchanges with the hydroxyl group in the bone mineral hydroxyapatite crystal to form fluoroapatite. ${ }^{15,21}$ Therefore, tracer uptake reflects bone remodeling and represents vascularized vital osseous tissue. The images showed uptake within the entire implant with a marked intensity at the anterior part, providing evidence of bone formation.

\section{Discussion}

In this paper, we demonstrate a scaffold designed for large cranial defect repair constituting ceramic tiles interconnected with titanium wires. The mosaic design, with space between each tile, allows for perioperative adjustments of the device but also provides free circulation of tissue fluids that may impact tissue integration and biological response.

The ceramic composition of the implant is crucial because the implant is intended to mimic coupled bone formation, which implies a balance between resorption of the ceramic compound and new bone deposition. Certain ceramic phases such as monetite, brushite and $\beta$-TCP, have in previous studies shown convincing osteoconductive properties, and for monetite, osteoinductive properties, and may be preferred choices for use in bone repair.,22 Conversely, these ceramic materials may resorb too quickly to allow for desired coupled bone formation. The ad- 


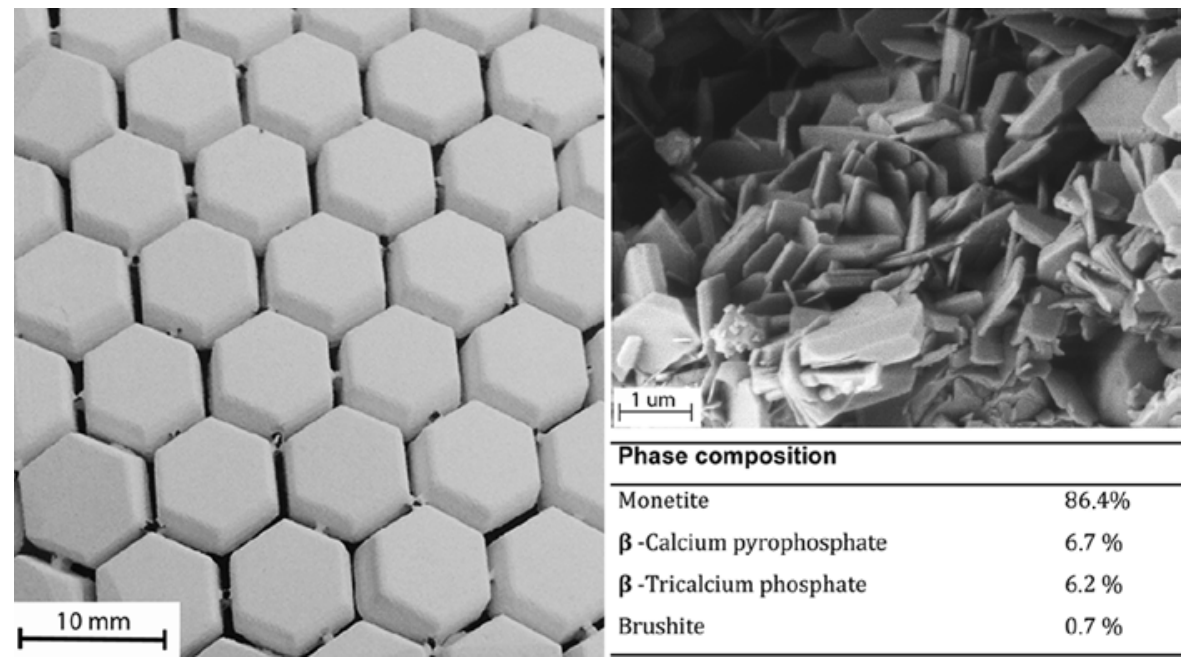

FIG. 1. Images and data of the bioactive implant. Left: Photograph showing the mosaic-designed implant comprising ceramic tiles interconnected with a titanium mesh. Upper right: Image from a scanning electron microscope showing the microstructure of the sterilized ceramic. The ceramic consists of entangled calcium phosphate crystals, mainly monetite according to $x$-ray diffraction, with a platelike structure and a grain size of approximately 1-2 $\mu \mathrm{m}$. Original magnification $\times 40,000$. Lower right: Table showing the specific composition of calcium phosphate phases used in the device.

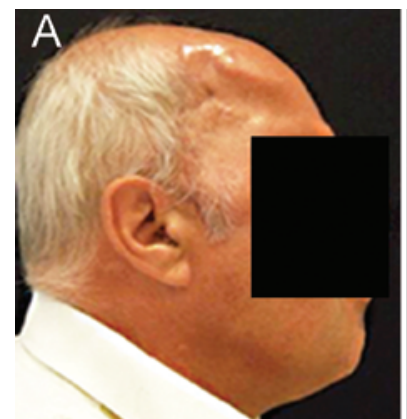

Before
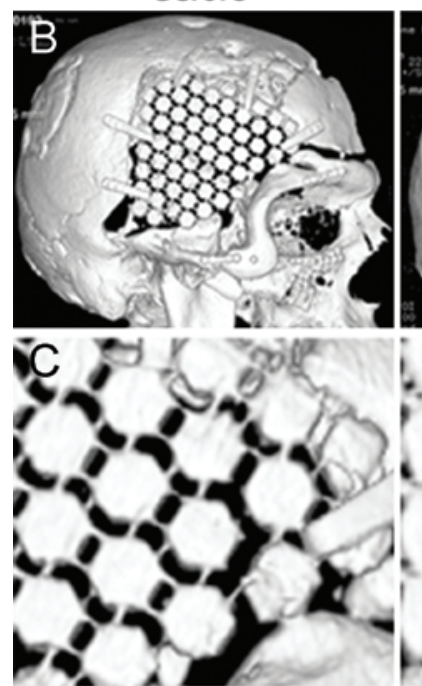

Day 1

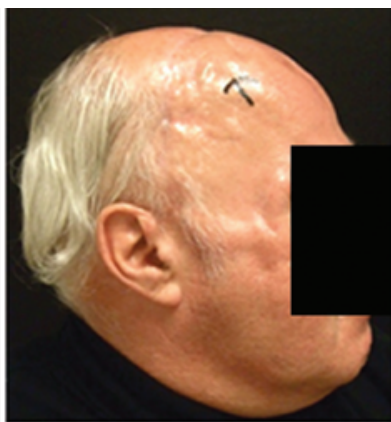

6 months
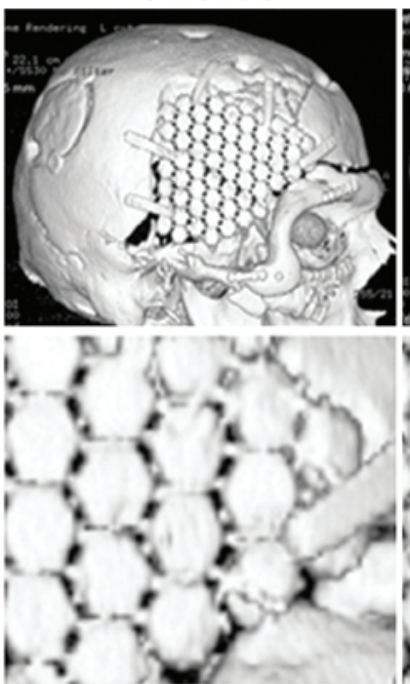

12 months

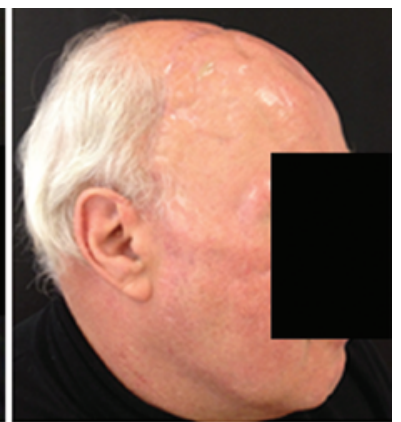

24 months
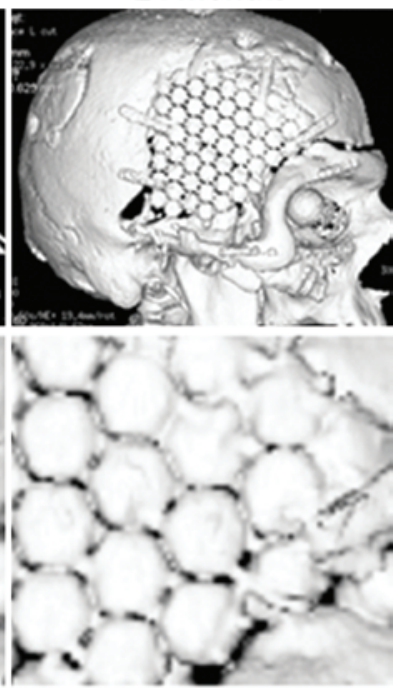

25 months

Fig. 2. Postoperative, 6-month, and 25-month follow-up photographs (A), CT scans (B), and close-up views (C) in the patient with the implant. The soft tissue covering the reconstructed right parietotemporal area was mainly thin and fibrotic due to the injury and previous surgery. Clinical follow-up examinations revealed intact or even improved quality of the skin over time after implantation (A). Consecutive CT scans showed progressive condensation of the ceramic tiles, which implied new deposition of radiopaque material within the implant $(\mathrm{B})$. Magnified images illustrate the frontal part of the reconstruction area (C). Original magnification $\times 5$. 


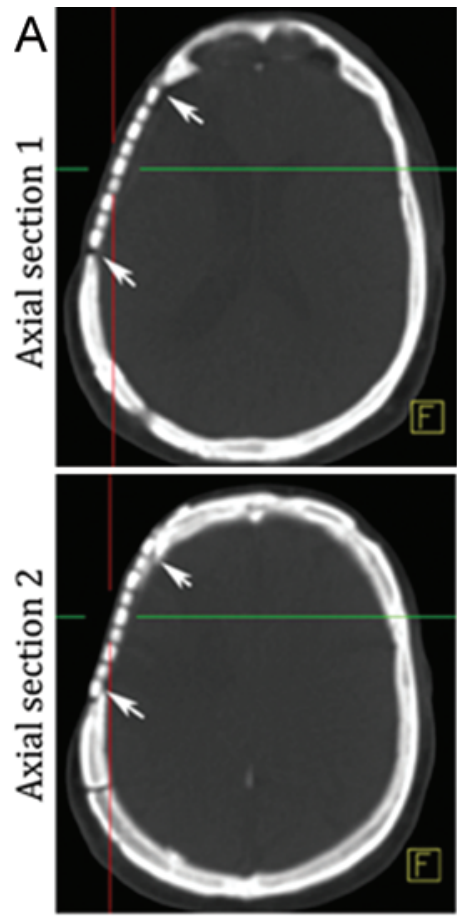

CT

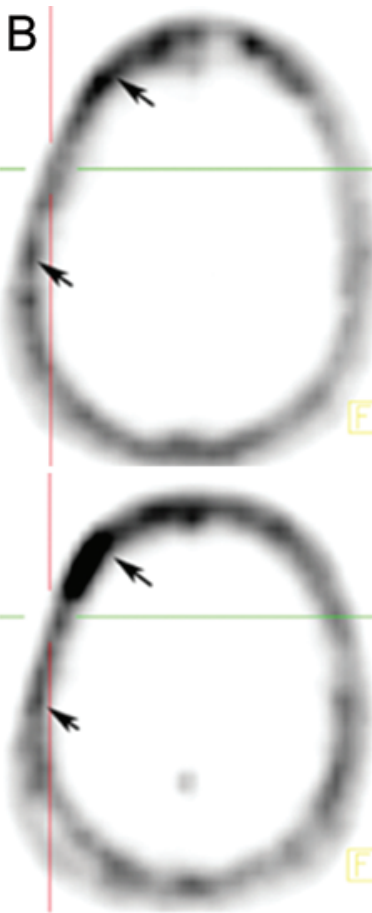

(18)F-Fluoride PET
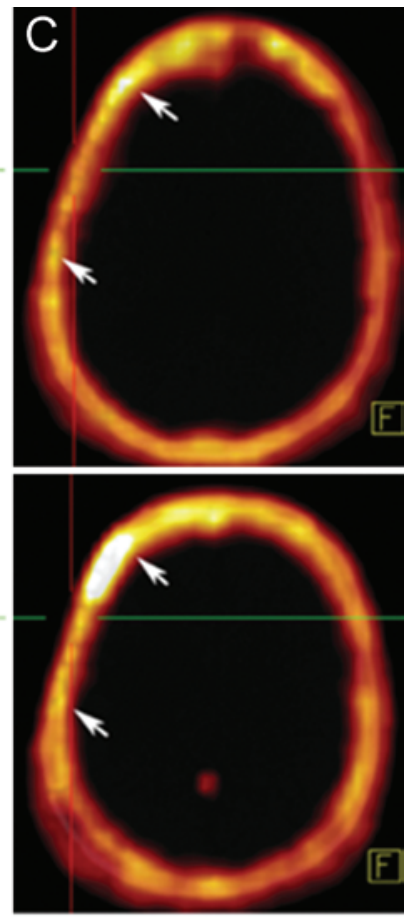

Combined CT/PET

FIG. 3. A combined PET/CT examination was performed to assess bone growth within the implant. The CT scans $(\mathrm{A})$, ${ }^{18} \mathrm{~F}-$ fluoride PET scans (B), and combined PET/CT scans (C) illustrate 2 representative axial sections from a patient with a cranial defect reconstructed with the mosaic device 27 months earlier. Arrows indicate borders of the implant. The PET images show bone activity within the entire implant, similar to adjacent cranial bone, and with intensified activity in the frontal part of the implant.

dition of $\beta$-PPi may be critical for prolonging resorption rate, allowing sufficient time for coupled bone formation to occur, and thereby realizing the implant's potential for bioactivity. This is supported by recent publications demonstrating the regulatory role of $\beta$-PPi on bone turnover based on controlling differentiation of osteoclast and osteoblast progenitor cells. ${ }^{10,16}$

The ${ }^{18} \mathrm{~F}$-fluoride PET/CT scans were used to refine localization of bone growth. The images revealed bone formation within the entire implant site, as well as in the central part of the implant. This indicates that the ceramic tiles may possess osteoinductive qualities because the tiles are separated from one another and are distally located from host bone. A particularly strong PET signal appeared in the anterior part of the reconstruction area, located within the frontal bone. The enhanced signal anteriorly may be explained by preclinical experiments demonstrating neural crest-derived frontal bone with a higher bone healing capacity as compared with parietal or temporal bones. ${ }^{18}$

\section{Conclusions}

On the basis of our experience with a severely injured and therapy-resistant patient, we have demonstrated successful cranial repair and healing by using a ceramic implant with a defined calcium phosphate composition. The follow-up duration was more than 30 months without clinical drawbacks. We believe that bone regeneration induced by the bioactive implant provides a permanent re- construction solution to the patient, thus diminishing the future risks of complications related to conventional methods, such as autologous bone grafts and inert alloplastic implants. The bioactive implant may represent a novel technique to induce ossification and healing of complicated bone defects within the craniofacial field, and more generally, in orthopedics. A case series with patients who suffered from conventional cranial implant or bone flap failures is in the planning stage. Moreover, a prospective study for cranial repair following decompressive craniectomy will be performed, in which the ceramic implant is compared with treatment with a preserved bone flap, the gold standard treatment, with a complication rate as high as $18 \%-25 \% .6,8,9$

\section{Disclosure}

A grant from the Swedish Innovation Agency Vinnova supported this study (no. 2011-00591). Drs. Engstrand, Bohlin, Åberg, and Engqvist all have direct ownership in OssDsign, the manufacturer of the implant that is the subject of this study. All are also patent holders in OssDsign.

Author contributions to the study and manuscript preparation include the following. Conception and design: Engstrand, Docherty Skogh, Bohlin, Åberg, Engqvist. Acquisition of data: Engstrand, Kihlström, Neovius, Docherty Skogh, Lundgren, Jacobsson, Bohlin, Engqvist. Analysis and interpretation of data: all authors. Drafting the article: Engstrand, Kihlström, Neovius, Jacobsson, Engqvist. Critically revising the article: all authors. Reviewed submitted version of manuscript: all authors. Approved the final version of the manuscript on behalf of all authors: Engstrand. Administrative/ technical/material support: all authors. Study supervision: Engstrand, Engqvist. 


\section{References}

1. Aberg J, Brisby H, Henriksson HB, Lindahl A, Thomsen P, Engqvist H: Premixed acidic calcium phosphate cement: characterization of strength and microstructure. J Biomed Mater Res B Appl Biomater 93:436-441, 2010

2. Apelt D, Theiss F, El-Warrak AO, Zlinszky K, Bettschart-Wolfisberger R, Bohner M, et al: In vivo behavior of three different injectable hydraulic calcium phosphate cements. Biomaterials 25:1439-1451, 2004

3. Cabraja M, Klein M, Lehmann TN: Long-term results following titanium cranioplasty of large skull defects. Neurosurg Focus 26(6):E10, 2009

4. Cenzi R, Farina A, Zuccarino L, Carinci F: Clinical outcome of 285 Medpor grafts used for craniofacial reconstruction. J Craniofac Surg 16:526-530, 2005

5. Dorozhkin SV: Bioceramics of calcium orthophosphates. Biomaterials 31:1465-1485, 2010

6. Gooch MR, Gin GE, Kenning TJ, German JW: Complications of cranioplasty following decompressive craniectomy: analysis of 62 cases. Neurosurg Focus 26(6):E9, 2009

7. Hannink G, Arts JJ: Bioresorbability, porosity and mechanical strength of bone substitutes: what is optimal for bone regeneration? Injury 42 (Suppl 2):S22-S25, 2011

8. Honeybul S, Ho KM: Long-term complications of decompressive craniectomy for head injury. J Neurotrauma 28:929-935, 2011

9. Honeybul S, Ho KM, Lind CR, Gillett GR: Observed versus predicted outcome for decompressive craniectomy: a population-based study. J Neurotrauma 27:1225-1232, 2010

10. Kim HJ, Minashima T, McCarthy EF, Winkles JA, Kirsch T: Progressive ankylosis protein (ANK) in osteoblasts and osteoclasts controls bone formation and bone remodeling. J Bone Miner Res 25:1771-1783, 2010

11. Lee JH, Chang BS, Jeung UO, Park KW, Kim MS, Lee CK: The first clinical trial of beta-calcium pyrophosphate as a novel bone graft extender in instrumented posterolateral lumbar fusion. Clin Orthop Surg 3:238-244, 2011

12. LeGeros RZ: Properties of osteoconductive biomaterials: calcium phosphates. Clin Orthop Relat Res (395):81-98, 2002

13. Lo KW, Ulery BD, Ashe KM, Laurencin CT: Studies of bone morphogenetic protein-based surgical repair. Adv Drug Deliv Rev 64:1277-1291, 2012

14. Marchac D, Greensmith A: Long-term experience with methylmethacrylate cranioplasty in craniofacial surgery. J Plast Reconstr Aesthet Surg 61:744-753, 2008

15. Marks SC Jr, Popoff SN: Bone cell biology: the regulation of development, structure, and function in the skeleton. Am J Anat 183:1-44, 1988

16. Nam HK, Liu J, Li Y, Kragor A, Hatch NE: Ectonucleotide py- rophosphatase/phosphodiesterase-1 (ENPP1) protein regulates osteoblast differentiation. J Biol Chem 286:39059-39071, 2011

17. Neovius E, Engstrand T: Craniofacial reconstruction with bone and biomaterials: review over the last 11 years. J Plast Reconstr Aesthet Surg 63:1615-1623, 2010

18. Quarto N, Wan DC, Kwan MD, Panetta NJ, Li S, Longaker MT: Origin matters: differences in embryonic tissue origin and Wnt signaling determine the osteogenic potential and healing capacity of frontal and parietal calvarial bones. J Bone Miner Res 25:1680-1694, 2010

19. Quarto R, Mastrogiacomo M, Cancedda R, Kutepov SM, Mukhachev V, Lavroukov A, et al: Repair of large bone defects with the use of autologous bone marrow stromal cells. N Engl J Med 344:385-386, 2001

20. Staffa G, Nataloni A, Compagnone C, Servadei F: Custom made cranioplasty prostheses in porous hydroxy-apatite using 3D design techniques: 7 years experience in 25 patients. Acta Neurochir (Wien) 149:161-170, 2007

21. Suenaga H, Yokoyama M, Yamaguchi K, Sasaki K: Time course of bone metabolism at the residual ridge beneath dentures observed using ${ }^{18} \mathrm{~F}$-fluoride positron emission computerized-tomography/computed tomography (PET/CT). Ann Nucl Med 26:817-822, 2012

22. Tamimi F, Torres J, Gbureck U, Lopez-Cabarcos E, Bassett DC, Alkhraisat MH, et al: Craniofacial vertical bone augmentation: a comparison between 3D printed monolithic monetite blocks and autologous onlay grafts in the rabbit. Biomaterials 30:6318-6326, 2009

23. Taylor BC, French BG, Fowler TT, Russell J, Poka A: Induced membrane technique for reconstruction to manage bone loss. $\mathbf{J}$ Am Acad Orthop Surg 20:142-150, 2012

24. Yuan H, Fernandes H, Habibovic P, de Boer J, Barradas AM, de Ruiter A, et al: Osteoinductive ceramics as a synthetic alternative to autologous bone grafting. Proc Natl Acad Sci U S A 107:13614-13619, 2010

Manuscript submitted January 8, 2013.

Accepted June 18, 2013.

Part of the study was presented at The International Society of Craniofacial Surgery 14th Biennial International Congress, August 27-September 1, 2011, in Livingstone, Zambia.

Please include this information when citing this paper: published online August 2, 2013; DOI: 10.3171/2013.6.JNS1360.

Address correspondence to: Thomas Engstrand, M.D., Department of Reconstructive Plastic Surgery, Karolinska University Hospital, Stockholm SE-171 76, Sweden. email: thomas.engstrand@ karolinska.se. 